Article

\title{
Physicians' Perception of E-Cigarettes as a Smoking Cessation Tool in Bangladesh
}

\author{
Merajul Islam ${ }^{1}$, Samia Amin ${ }^{2, *}$
}

How to cite this paper: Islam, M., \& Amin, S. (2021). Physicians' Perception of E-Cigarettes as a Smoking

Cessation Tool in Bangladesh. Current Research in Public Health, 1(1), 812. Retrieved from https://www.scipublications.com/journal/index.php/crph/article/view/90

Received: July 12, 2021

Accepted: August 14, 2021

Published: August 15, 2021

Copyright: (c) 2021 by the authors. Submitted for possible open access publication under the terms and conditions of the Creative Commons Attribution (CC BY) license (http://creativecommons.org/licenses /by/4.0/).

${ }^{1}$ Abdul Samad Memorial Hospital, Thinadhoo, Maldives

${ }^{2}$ Macquarie University, Sydney, Australia

*Correspondence: drsamia27@gmail.com

\begin{abstract}
The popularity of e-cigarette is growing worldwide. Its health hazards and role in smoking cessation is controversial. There is no doubt that health care professionals can play a vital role in assisting patients who wish to use e-cigarettes to quit smoking but there is a gap in the evidence. The present study aimed to reveal the perception of e-cigarettes as a quit smoking tool and its health hazards among physicians in Bangladesh. A cross-sectional study was conducted by means of a survey via self-administered structured questionnaires in Bangladesh. Data was collected from September 2019 to February 2020 and analysed by descriptive frequency and chi-square test using SPSS. A total of 145 physicians have participated in this study, $88.9 \%$ provided professional advice on quit smoking to their patients. Total $51.7 \%, 51.9 \%, 41.3 \%, 52.4 \%, 42.8 \%$, and $47.6 \%$ physicians mentioned that e-cigarettes may cause throat irritations, cough, headache, dryness of mouth, cardiovascular disease, and cancer respectively. Chi-square test revealed that there is no association between a physician's professional advice for quit smoking and perception of e-cigarettes as a smoking cessation tool. The physician's perception of e-cigarettes is crucial for reducing any type of tobacco consumption. Evidence based e-cigarette related public health intervention for physicians are required to mitigate the use of e-cigarette to quit smoking.
\end{abstract}

Keywords: E-cigarette, Smoking, Smoking Cessation, Health hazard, Physician, Bangladesh

\section{Introduction}

Electronic cigarettes (e-cigarettes) generate an aerosolized mixture containing flavoured liquids and nicotine to inhale [1]. Many people around the globe trying to quit smoking using e-cigarettes more frequently than approved cessation aids [2]. Although e-cigarettes contain a lower nicotine level $(0.025-0.77 \mathrm{mg} / 15 \mathrm{puffs})$ than conventional cigarettes (1.54-2.60 mg per cigarette) [3], but few studies claim that it contains carcinogenic compound namely nitrosamines, carbonyls, polycyclic aromatic hydrocarbons [4]. Additionally, studies also found a link between e-cigarettes with cardiovascular [5] and lung [6] disease.

Evidence suggests smokers use e-cigarettes as a quit smoking tool $[7,8]$. However, experimentation with e-cigarettes is increasing rapidly among adolescents and non-smokers $[9,10]$. Health care professionals especially the physicians should be aware of how ecigarettes are used or misused to assess patient's tobacco related morbidity and mortality. Physicians can support patients to quit smoking by providing accurate and unbiased information of e-cigarettes to make informed choices about their health and lifestyle. As evidence is mixed about the ability of e-cigarettes to help smokers achieve long-term abstinence [11,12], hence behavioural counselling, pharmacological intervention and appropriate referral resource aids are essential for a quit attempt to be successful [8].

A National Survey in the United States revealed that approximately two-thirds physicians frequently assist patients to quit smoking and $38 \%$ of doctors recommended e- 
cigarettes to their patients who smoke [13]. Similarly, smokers are most often identified, advised, and offered quit smoking support in a clinical setting in Bangladesh which is vital for the identification and referral of smokers to take place. However, there is limited evidence on the use of e-cigarettes as quit smoking aid in the context of the clinical setting in Bangladesh. This study addressed the gap regarding the physician's perception of ecigarettes as a smoking cessation tool and its health hazards in Bangladesh.

\section{Materials and Methods}

The present study used a cross-sectional survey. Convenience and snowball sampling methods were used to select the physicians as a respondent in Bangladesh. Two prescreening questions were asked to identify possible respondents, hence only respondents who were practicing medical doctor in Bangladesh and had heard about e-cigarettes qualified to participate in the study. However, respondents did not need to identify any of the brands or types of e-cigarettes.

The survey questionnaire was prepared through the Google Form platform. The questionnaire was distributed through emails, social media channels which is Facebook, links of contacts and friend-to-friend. The questionnaire consists of a total of 20 questions including physician's sociodemographic, smoking, and vaping status, e-cigarette related health hazards and perception about e-cigarettes as a smoking cessation tool. The questionnaire was developed by an extensive review of the literature and discussed among the research team to ensure the relevance of each item and content validity. The survey questionnaire was pilot tested in a sample with similar characteristics which were excluded from the main analysis to determine the usability of the online response system, language clarity and timing of the questions.

Participants' socio-demographic data including gender and professional experience level were collected. Other than that, tobacco consumption habit was recorded based on participants smoking (smoker who had smoked 100 cigarettes in their lifetime and nonsmoker who never smoked cigarettes) and vaping status (vaper who had used e-cigarettes more than a month in their lifetime and non-vaper who had never used e-cigarettes). Ecigarettes related health risk questions were based on a 5 Likert scale consisting of strongly disagree to strongly agree. Regarding the physician's perception about e-cigarettes as a smoking cessation tool, a total of 5 dichotomous statements were incorporated with binary answers as 'disagree/agree'. The statements were as follows, e-cigarettes are (1) less harmful than smoking; (2) help in smoking cessation; (3) help smokers to cut down the number of cigarettes; (4) satisfy the desire to smoke among the smokers and (5) taste pleasant than conventional smoking.

Data was collected from September 2019 to February 2020. Consent for the study was achieved by describing the study purpose to the participants and ethical guidelines of the Declaration of Helsinki IV were followed. Physicians who voluntarily agreed to participate in the study were included in the survey. Data were analysed using Statistical Package for the Social Sciences version 25.0 (SPSS Inc, Chicago, IL, USA) and a statistical level of $p<0.05$ was considered significant. All the variables in this study were normally distributed. The descriptive statistic was presented in the frequencies and percentages and bivariate analysis of chi-square $\left(\chi^{2}\right)$ was used to measure associations between two categorical variables.

\section{Results}

Total of 145 physicians from Bangladesh was involved in this study, 68.2\% (99 out of 145 ) were male doctor. Total $93.1 \%$ (135 out of 145 ) were professionally experienced less than 5 years and $88.9 \%$ (129 out of 145) provided professional advice on quit smoking to their patient. The percentage of non-smokers $(n=121,83.4 \%)$ and non-vaper $(n=133,91.7 \%)$ 
respondents were predominant. Surprisingly, 12 out of 145 (8.2\%) physicians used e-cigarettes users. Total $128(88.2 \%)$ physicians heard about e-cigarette and 90 (62.0\%) seen someone using e-cigarettes. Remarkably, 86 (59.3\%) physicians had read e-cigarette related scientific articles.

The questions regarding e-cigarette related health hazards were assessed through Likert-scale based answer with 'strongly disagree' to 'strongly agree' options. Based on Table 1, most of the physicians stated 'neural' responses. Total 51.7\%, 51.9\%, 41.3\%, 52.4\%, $42.8 \%$ and $47.6 \%$ physicians cumulatively 'agree' and 'strongly agreed' that e-cigarettes may cause throat irritations, cough, headache, dryness of mouth, cardiovascular disease, and cancer respectively (Table 1 ).

Table 1. Distribution of physician's responses about e-cigarette related health hazards $(\mathrm{N}=145)$

\begin{tabular}{lccccc}
\hline \multicolumn{1}{c}{ Statement } & $\begin{array}{c}\text { Strongly } \\
\text { Disagree } \\
\mathbf{N ~ ( \% )}\end{array}$ & $\begin{array}{c}\text { Disagree } \\
\mathbf{N ~ ( \% )}\end{array}$ & $\begin{array}{c}\text { Neutral } \\
\mathbf{N ~ ( \% )}\end{array}$ & $\begin{array}{c}\text { Agree } \\
\mathbf{N ~ ( \% )}\end{array}$ & $\begin{array}{c}\text { Strongly } \\
\text { Agree } \\
\mathbf{N ~ ( \% )}\end{array}$ \\
\hline E-cigarettes may cause & & & & & \\
\hline - Throat irritations & $8(5.5 \%)$ & $5(3.4 \%)$ & $57(39.3 \%)$ & $37(25.5 \%)$ & $38(26.2 \%)$ \\
\hline - Cough & $13(9.0 \%)$ & $9(6.2 \%)$ & $48(33.1 \%)$ & $35(24.1 \%)$ & $40(27.6 \%)$ \\
\hline - Headache & $14(9.7 \%)$ & $12(8.3 \%)$ & $59(40.7 \%)$ & $26(17.9 \%)$ & $34(23.4 \%)$ \\
\hline - Dryness of mouth & $6(4.1 \%)$ & $5(3.4 \%)$ & $58(40.0 \%)$ & $40(27.6 \%)$ & $36(24.8 \%)$ \\
\hline - Cardiovascular disease & $24(16.6 \%)$ & $22(15.2 \%)$ & $37(25.5 \%)$ & $31(21.4 \%)$ & $31(21.4 \%)$ \\
\hline - Cancer & $13(9.0 \%)$ & $13(9.0 \%)$ & $50(34.5 \%)$ & $32(22.1 \%)$ & $37(25.5 \%)$ \\
\hline
\end{tabular}

Table 2 showed the results of the bivariate analysis examining the association between physician's professional advice for quit smoking and perception of e-cigarettes as a smoking cessation tool. However, from the bivariate analysis all the independent variables of perception of e-cigarettes as a smoking cessation tool did not show any significant association with the physician's professional advice (Table 2). All the statements such as, E-cigarettes are less harmful than smoking $(\chi 2=1.75, \mathrm{p}=0.18)$, E-cigarettes can help in smoking cessation $(\chi 2=1.05, p=0.30)$, E-cigarettes might help smokers to cut down the number of cigarettes $(\chi 2=1.31, \mathrm{p}=0.25)$, E-cigarettes might satisfy the desire to smoke among the smokers $(\chi 2=1.04, p=0.83)$, and E-cigarettes might taste pleasant than conventional smoking $(\chi 2=1.61, \mathrm{p}=0.93)$ were not statically significant.

Table 2. Association between physician's professional advice for quit smoking and perception of e-cigarettes $(\mathrm{N}=145)$

\begin{tabular}{|c|c|c|c|c|c|}
\hline & & \multicolumn{2}{|c|}{$\begin{array}{l}\text { Physicians' role as } \\
\text { quit smoking adviser }\end{array}$} & \multirow[t]{2}{*}{$\chi^{2}$} & \multirow[t]{2}{*}{$\begin{array}{c}\text { p-value } \\
\substack{\text { Significant at level } \\
\text { p }<0.05} \\
\end{array}$} \\
\hline & & $\begin{array}{l}\text { Yes } \\
\text { N (\%) }\end{array}$ & $\begin{array}{c}\text { No } \\
\text { N (\%) }\end{array}$ & & \\
\hline $\begin{array}{l}\text { E-cigarettes are less harmful than } \\
\text { smoking }\end{array}$ & $\begin{array}{l}\text { Disagree } \\
\text { Agree }\end{array}$ & $\begin{array}{l}71(55.0) \\
58(45.0)\end{array}$ & $\begin{array}{c}6(37.5) \\
10(62.5)\end{array}$ & 1.75 & 0.18 \\
\hline $\begin{array}{l}\text { E-cigarettes can help in smoking } \\
\text { cessation }\end{array}$ & $\begin{array}{l}\text { Disagree } \\
\text { Agree }\end{array}$ & $\begin{array}{l}89(69.0) \\
40(31.0)\end{array}$ & $\begin{array}{l}9(56.3) \\
7(43.7) \\
\end{array}$ & 1.05 & 0.30 \\
\hline $\begin{array}{l}\text { E-cigarettes might help smokers to cut } \\
\text { down the number of cigarettes }\end{array}$ & $\begin{array}{c}\text { Disagree } \\
\text { Agree } \\
\end{array}$ & $\begin{array}{l}68(52.7) \\
61(47.3)\end{array}$ & $\begin{array}{c}6(37.5) \\
10(62.5) \\
\end{array}$ & 1.31 & 0.25 \\
\hline $\begin{array}{l}\text { E-cigarettes might satisfy the desire to } \\
\text { smoke among the smokers }\end{array}$ & $\begin{array}{l}\text { Disagree } \\
\text { Agree }\end{array}$ & $\begin{array}{l}68(52.7) \\
61(47.3) \\
\end{array}$ & $\begin{array}{l}8(50.0) \\
8(50.0)\end{array}$ & 1.04 & 0.83 \\
\hline $\begin{array}{l}\text { E-cigarettes might taste pleasant than } \\
\text { conventional smoking }\end{array}$ & $\begin{array}{l}\text { Disagree } \\
\text { Agree }\end{array}$ & $\begin{array}{l}66(51.1) \\
63(48.9)\end{array}$ & $\begin{array}{l}8(50.0) \\
8(50.0)\end{array}$ & 1.61 & 0.93 \\
\hline
\end{tabular}




\section{Discussion}

In this study, the majority of the physician heard about e-cigarette; had read e-cigarette related scientific articles and seen someone using e-cigarettes. Shockingly, few physicians were vaper. Further, the majority of the physicians were recent practitioners who professionally experienced less than 5 years but provided professional advice on quit smoking to their patients. Additionally, the physician's professional advice for quit smoking was not associated with the perception of e-cigarettes as a smoking cessation tool.

E-cigarettes are designed to support smoking cessation tool [7], but the evidence is still inconclusive [11]. In this study, the physician's perception of e-cigarettes as a smoking cessation tool was consistent with prior studies $[7,11,12]$ where participants considered ecigarettes would positively influence the cessation of smoking, but there was no sound conclusion on this point. Additionally, participants from other studies [7,11,12] also recognised that e-cigarettes had a primary use for helping to quit conventional cigarettes, although different factors influenced their perception of their use as alternatives, such as pleasant taste, management of nicotine craving, reduce the number of cigarettes which is coherent with this current study findings.

The perceived health risk of e-cigarettes was assessed by several studies $[14,15]$ where participants believe that vaping is safer than smoking. On the contrary, the majority of the physicians in this study perceived that e-cigarette have various health hazards. In another study at the point of consumer perspective, approximately one in three youth participants perceived e-cigarettes as less harmful than conventional cigarettes [16]. But evidence suggest that the concept is changing over time, perception of the harmfulness of e-cigarettes increased significantly from 2012 to 2017 [17]. And an interesting additional finding of this present study is that physicians read about scientific articles to know about e-cigarette related evidence which is very promising.

The sampling method of this study limits the generalizability of the findings. Further, although current analysis could not infer causal relationships, till date, this is the only study which measured the perception of e-cigarettes among the physicians in Bangladesh. Most smokers intend to quit smoking but barrier such as lack of support to quit smoking from the health service provider is a considerable concern. Hence, future intervention programs should focus to coach physicians about the role of e-cigarettes in smoking cessation along with other pharmacotherapeutic and behavioural interventions. Subsequently, if the smoker intent to use e-cigarettes as their quit smoking tool, physicians can provide evidence-based information to the smokers to consider informed decision about vaping to quit smoking.

\section{Conclusions}

Based on the findings, it can be concluded that physicians in Bangladesh are aware of e-cigarettes, its health risks, and impact on smoking cessation. This research can be used as a basis to develop further research on the role of physicians to minimize the use of ecigarettes including both smokers and non-smokers in Bangladesh.

Author Contributions: Conceptualization, S.A.; writing-review and editing, M.I and S.A.; supervision, S.A.

Funding: This research received no funding.

Data Availability Statement: Data is not publicly available, only available by requesting email to corresponding author.

Acknowledgments: Participants for their valuable time and support.

Conflicts of Interest: The authors declare no conflict of interest. 


\section{References}

[1] Grana R, Benowitz N, Glantz SA. E-cigarettes: a scientific review. Circulation. 2014; 129:1972-1986. doi: https://doi.org/10.1161/ CIRCULATIONAHA.114.007667

[2] Benmarhnia T, Pierce JP, Leas E, et al., Can e-cigarettes and pharmaceutical aids increase smoking cessation and reduce cigarette consumption? Findings from a nationally representative cohort of American smokers. American Journal of Epidemiology. 2018; 187: 2397-404. doi: https://doi.org/10.1093/aje/kwy129

[3] Goniewicz ML, Knysak J, Gawron M, et al., Levels of selected carcinogens and toxicants in vapour from electronic cigarettes. Tobacco Control. 2014; 23:133-139. doi: http://dx.doi.org/10.1136/tobaccocontrol-2012-050859

[4] Pisinger C, Døssing M, A systematic review of health effects of electronic cigarettes, Preventive Medicine, 2014; 69: 248-260. doi: https://doi.org/10.1016/j.ypmed.2014.10.009

[5] MacDonald A, Middlekauff HR. Electronic cigarettes and cardiovascular health: what do we know so far? Vascular Health and Risk Management. 2019; 15:159-174. doi: https://doi.org/10.2147/VHRM.S175970

[6] Bhatta DN, Glantz SA. Association of e-cigarette use with respiratory disease among adults: a longitudinal analysis. American Journal of Preventive Medicine. 2020;58(2):182-190. doi: https://doi.org/10.1016/j.amepre.2019.07.028

[7] Rahman MA, Hann N, Wilson A, et al., E-cigarettes and smoking cessation: evidence from a systematic review and meta-analysis. PLoS One. 2015;10(3): e0122544. doi: https://doi.org/10.1371/journal.pone.0122544

[8] Hajek P, Phillips-Waller A, Przulj D, et al., A randomized trial of e-cigarettes versus nicotine-replacement therapy. The New England Journal of Medicine. 2019;380(7):629-637. doi: https://doi.org/10.1056/NEJMoa1808779

[9] Evans-Polce RJ, Patrick ME, Lanza ST, et al., Reasons for vaping among U.S. 12th graders. The Journal of Adolescent Health. 2018;62(4):457-462. doi: https://doi.org/10.1016/j.jadohealth.2017.10.009

[10] Pepper JK, Ribisl KM, Brewer NT, Adolescents' interest in trying flavoured e cigarettes. Tobacco Control. 2016;25: ii62-ii66. doi: http://dx.doi.org/10.1136/tobaccocontrol-2016-053174

[11] Malas M, van der Tempel J, Schwartz R, et al., Electronic cigarettes for smoking cessation: a systematic review. Nicotine $\mathcal{E}$ Tobacco Research, 2016;18(10):1926-1936. doi: https://doi.org/10.1093/ntr/ntw119

[12] Kalkhoran S, Glantz SA. E-cigarettes and smoking cessation in real-world and clinical settings: a systematic review and metaanalysis. The Lancet Respiratory Medicine. 2016;4(2): 116-128. doi: https://doi.org/10.1016/S2213-2600(15)00521-4

[13] Nickels AS, Warner DO, Jenkins SM, et al., Beliefs, practices, and self-efficacy of US physicians regarding smoking cessation and electronic cigarettes: a national survey. Nicotine E Tobacco Research. 2017;19(2):197-207. doi: https://doi.org/10.1093/ntr/ ntw194

[14] Churchill V, Nyman AL, Weaver SR, et al., Perceived risk of electronic cigarettes compared with combustible cigarettes: direct versus indirect questioning. Tobacco Control. 2020; 0:1-3. doi: http://dx.doi.org/10.1136/tobaccocontrol-2019-055404

[15] Amrock SM, Lee L, Weitzman M. Perceptions of e-cigarettes and noncigarette tobacco products among US youth. Paediatrics. 2016;138(5): e20154306. doi: https://doi.org/10.1542/peds.2015-4306

[16] Ambrose BK, Rostron BL, Johnson SE, et al., Perceptions of the relative harm of cigarettes and e-cigarettes among U.S. youth. American Journal of Preventive Medicine. 2014;47(2 Suppl 1): S53-S60. doi: https://doi.org/10.1016/j.amepre.2014.04.016

[17] Huang J, Feng B, Weaver SR, et al., Changing perceptions of harm of e-cigarette vs cigarette use among adults in 2 US national surveys from 2012 to 2017. JAMA network open, 2019, 2(3): e191047. doi: https://doi.org/10.1001/jamanetworkopen.2019.1047 